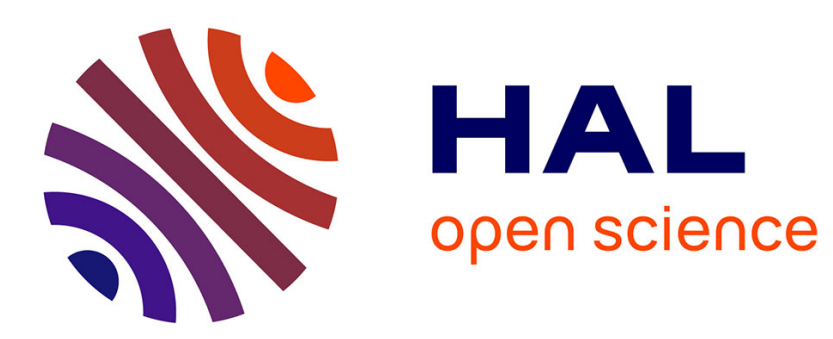

\title{
Do changes in the azimuthal distribution of maize leaves over time affect canopy light absorption?
}

\author{
Jean-Louis Drouet, Bruno B. Moulia, Raymond Bonhomme
}

\section{To cite this version:}

Jean-Louis Drouet, Bruno B. Moulia, Raymond Bonhomme. Do changes in the azimuthal distribution of maize leaves over time affect canopy light absorption?. Agronomie, 1999, 19 (3-4), pp.281-294. hal00885930

\section{HAL Id: hal-00885930 \\ https://hal.science/hal-00885930}

Submitted on 1 Jan 1999

HAL is a multi-disciplinary open access archive for the deposit and dissemination of scientific research documents, whether they are published or not. The documents may come from teaching and research institutions in France or abroad, or from public or private research centers.
L'archive ouverte pluridisciplinaire HAL, est destinée au dépôt et à la diffusion de documents scientifiques de niveau recherche, publiés ou non, émanant des établissements d'enseignement et de recherche français ou étrangers, des laboratoires publics ou privés. 


\title{
Do changes in the azimuthal distribution of maize leaves over time affect canopy light absorption?
}

\author{
Jean-Louis Drouet ${ }^{\mathrm{a}, *}$, Bruno Moulia $^{\mathrm{b}}$, Raymond Bonhomme ${ }^{\mathrm{a}}$ \\ ${ }^{a}$ Unité de recherche en bioclimatologie, Inra, 78850 Thiverval-Grignon, France \\ ${ }^{\mathrm{b}}$ Station d'écophysiologie des plantes fourragères, Inra, 86600 Lusignan, France
}

(Received 16 September 1998; accepted 22 February 1999)

\begin{abstract}
In maize canopies, when modelling the architecture and light regime one usually assumes leaf azimuths are distributed uniformly. Once we had demonstrated azimuthal re-orientation of maize leaves during the vegetative phase, we tested the weight of this hypothesis on the light absorbed daily by the canopy. We thus modelled the three-dimensional (3D) geometry of maize canopies with various plant densities and at different developmental stages using plant digitizing under field conditions. We simulated radiative transfer using a volume-based approach within actual and hypothetical canopies, obtained by simply rearranging leaf azimuths. Simulations indicated that changes to horizontal heterogeneity have little effect on daily light absorption efficiency. It is concluded that changes in leaf azimuths do not have to be taken into account in crop-functioning models. (C Inra/Elsevier, Paris.)
\end{abstract}

\section{leaf azimuth / leaf re-orientation / light absorption / simulation / maize}

Résumé - Les variations au cours du temps de la répartition spatiale des feuilles de maïs influencent-elles l'absorption du rayonnement par le couvert ? Pour les couverts de maïs, les modèles d'architecture des plantes et de transferts radiatifs utilisent classiquement l'hypothèse d'une répartition aléatoire des feuilles en azimut. Ayant précédemment mis en évidence des ré-orientations azimutales des feuilles de maïs au cours de la phase végétative, nous avons testé le poids de cette hypothèse sur l'absorption journalière de lumière par le couvert. Pour cela, nous avons modélisé la géométrie en trois dimensions (3D) de couverts de maïs de densités et de stades phénologiques différents à partir de digitalisations de plantes au champ. Nous avons ensuite simulé les échanges radiatifs à l'aide d'un modèle volumique dans les couverts observés et dans des couverts hypothétiques obtenus en modifiant uniquement les azimuts foliaires. Les simulations indiquent que les variations d'hétérogénéité horizontale ont peu d'influence sur l'efficience journalière d'absorption de la lumière. Il n'est donc pas nécessaire de prendre en compte les variations d'azimuts foliaires dans les modèles de fonctionnement des cultures. († Inra/Elsevier, Paris.)

azimut foliaire / ré-orientation foliaire / absorption du rayonnement / simulation / maïs

Communicated by Gérard Guyot (Avignon, France)

* Correspondence and reprints

drouet@bcgn.grignon.inra.fr 


\section{Introduction}

Studying the radiative regime within crops is an important area in agronomic research, because irradiance is one of the main factors that affects leaf photosynthesis and plant growth. The increasing complexity of these models has greatly influenced the way in which the architecture of a plant is studied.

The first radiative models $[4,25]$ were based on the analogy between the canopy and a turbid medium (see reviews in $[18,28,34,41]$ ). They were only applied to horizontally homogeneous crops with randomly distributed leaf elements. Modelling radiative exchange between canopy layers required a description of the canopy structure according to a vertical axis [27, 34, 36]. Most studies, therefore, focused on the vertical heterogeneity of leaf area and leaf inclination $[9,22,27,34,44]$.

Conversely, horizontal heterogeneity in the canopy structure has received much less attention. In models of maize canopy architecture [32, 36], one usually assumes that all the leaves lie within the same vertical plane, due to distichous phyllotaxy [21]. The azimuthal orientation of this plane is also assumed to be uniform owing to the random orientation of seeds from mechanical planting [29, 35].

As the turbid-medium approach was extended to row crops (see [38]), and surface-based models of light transfer were developed [5, 6, 19], a precise description of the aerial architecture of the canopy was required. Furthermore, architectural models of plant growth $[12,33]$ or studies on competition for light interception between crops and weeds $[1,11]$ necessitated more in-depth investigation of the changes in leaf spatial orientation over time.

Leaf display pattern has been largely discussed in terms of an adaptive strategy for light capture and carbon gain $([17,20]$ among others). However, since studies on the horizontal heterogeneity of foliage have not been greatly developed, few studies have analysed the effect of changes to horizontal leaf area distribution on the light regime within canopies. To our knowledge, there are currently no such studies available on maize.

We focused first on azimuthal re-orientation in maize leaves during the vegetative period. We then simulated the three-dimensional (3D) architecture of the canopy and generated hypothetical canopies by changing leaf azimuthal positions according to the leaf movements observed over time. We evaluated the influence of these changes to plant architecture on the light absorbed daily by the canopy. Finally, we discussed our results from both the points of view of plant functioning and that of modelling.

\section{Leaf azimuthal re-orientations during the vegetative phase}

Although the azimuthal positioning of maize leaves has not been widely analysed, some authors have noted a tendency for maize leaves to display within the inter-rows, especially after stand closure [22, 24, 34, 37]. Recently, Girardin and Tollenaar investigated leaf azimuthal changes during the development of a maize crop [14-16]. In field experiments $[14,16]$, an increasing trend for the successive leaves to twist their azimuth toward a final position perpendicular to the row was observed. In a growth-chamber experiment [15], three initial azimuthal patterns were imposed and a strong azimuthal re-orientation in successive maize leaves over time was found. However, the middle leaves tended to a uniform azimuthal distribution, with only the top leaves tending to a perpendicular position. Drouet and Moulia [8] repeated these initial patterns under field conditions, and their results were partially in accordance with those obtained by Girardin and Tollenaar.

\subsection{Field experiment design}

In the field experiment, maize was sown at a density of 10 plants $\mathrm{m}^{-2}$. The rows ran north-south to ensure symmetrical daily incident radiation. To maximize leaf re-orientation, the following approach was used to obtain two initial azimuthal 
Figure 1. Mean and circular standard deviation of the difference in leaf azimuth between two successive dates of measurements for (O) leaf 9 in the perpendicular plot, $(\bigcirc)$ leaf 9 in the parallel plot, $(\mathbf{A})$ leaf 10 in the perpendicular plot, $(\triangle)$ leaf 10 in the parallel plot, $(\square)$ leaf 11 in the perpendicular plot, $(\square)$ leaf 11 in the parallel plot. The values for any date correspond to the difference between the leaf azimuth at this date of measurement and the leaf azimuth at the previous date of measurement, divided by the time between these two dates.

Figure 2. Frequencies of the differences between leaf azimuths at silking and initial plant azimuths in the perpendicular plot (a) leaves $6-8$, (b) leaves $9-11$, (c) leaves $12-14$, and in the parallel plot (d) leaves $6-8$, (e) leaves $9-11$, (f) leaves $12-14$.
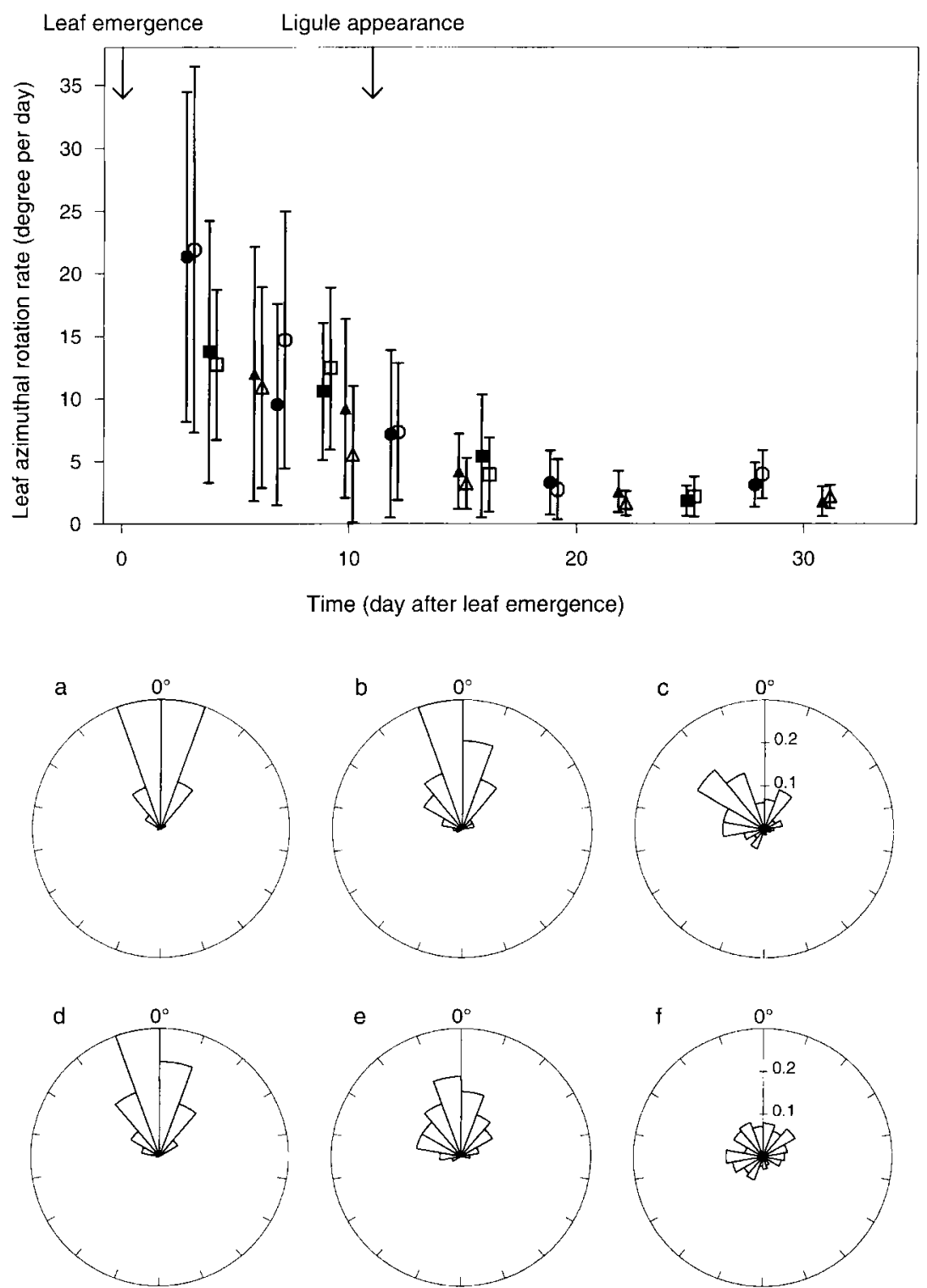

patterns. As the field plots were sown, another group of seedlings was grown outside in containers made of peat, until the emergence of the tip of the fourth leaf. In the first plot (called perpendicular), maize seedlings were transplanted with their azimuthal plane perpendicular to the row. In the second plot (called parallel), maize seedlings were transplanted with their azimuthal plane parallel to the row (see [8] for more details).

Azimuth angles of the lower part (base azimuth) and the tip (tip azimuth) of each visible lamina were measured to within 10 degrees and clockwise from the north. We found that each individual maize lamina lay mainly within a vertical plane, as reported by Sinoquet et al. [39], and we therefore only studied lamina base azimuths. The azimuthal plane of each plant (called the initial plant azimuth) was defined from the azimuth angle of lamina 2-4 measured at the six-leaf stage. From the nine-leaf stage to silking, measurements were taken once or twice a week. Directional data were analysed after Fisher [10] (see [8] for more details). 


\subsection{Changes to leaf azimuths over time}

Our study [8] confirmed that large azimuthal changes to leaf orientation occur in maize, as reported by Girardin and Tollenaar [14-16], and the azimuth of successive leaves within a given plant varies from the plant azimuth, in accordance with Sinoquet et al. [39]. For all leaves, azimuthal re-orientation was essentially observed before ligule appearance. In the first 4 days after tip emergence, leaves experienced noticeable azimuthal reorientation: from 10 to 20 degrees per day on average (figure 1 ). The intensity of these movements decreased with time, and only a few small movements occurred after ligule appearance, especially for the longer leaves $(9,10$ and 11): from 3 to 8 degrees per day on average (figure 1 ).

We found that initial plant orientation had a strong effect on final leaf azimuthal dispersion $(f i g$ ure 2). At the bottom of the canopy (leaf numbers
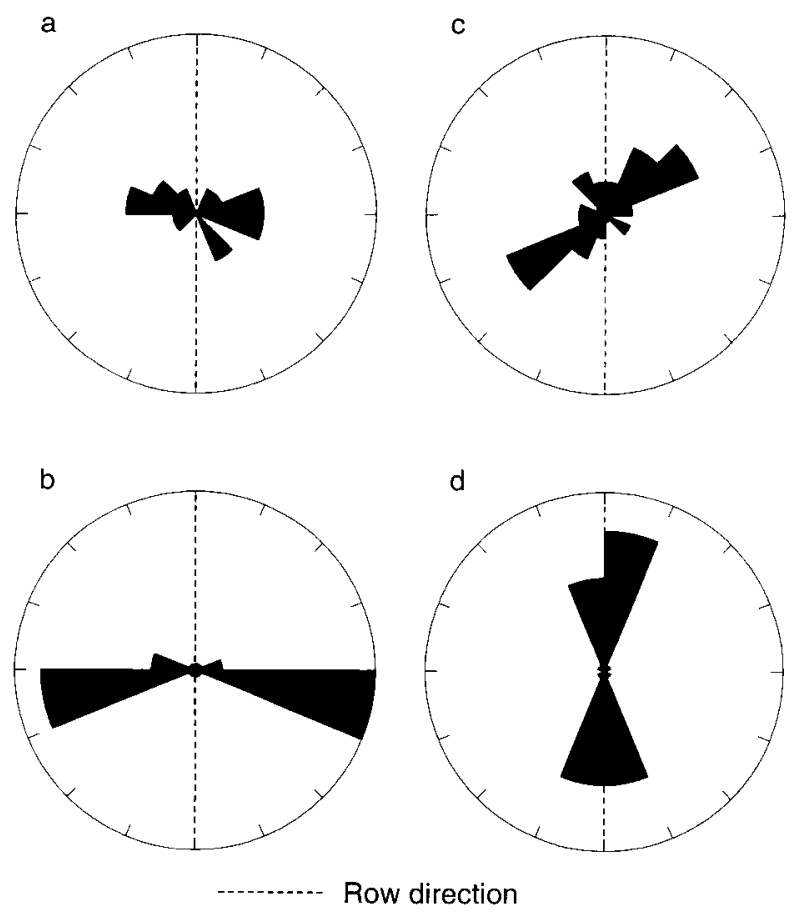

Figure 3. Azimuths of (a) leaves 14 and 15, and (b) leaves 6 and 7 of 18 DEA maize plants initially orientated perpendicular to the row. Azimuths of (c) leaves 14 and 15, and (d) leaves 6 and 7 of 20 P3902 maize plants initially orientated parallel to the row (after [16]). from 6 to 8 ), distribution tended to be normal with low dispersion. Dispersion increased in the middle layers of the canopy (leaf ranks from 9 to 11 ). At the top of the canopy (leaf numbers from 12 to 14), azimuthal distribution tended to be uniform, especially in the parallel plot (figure 2, see [8] for more details and statistical analysis). Increased clumping in the initial canopy pattern provoked an increased reaction in the leaves towards uniform azimuthal distribution. As Girardin and Tollenaar [15], who conducted experiments under controlled conditions with similar initial plant patterns, we found a tendency under field conditions for the azimuths of longer leaves to disperse (from 9 to 11 , in the middle layers of the canopy), regardless of the initial plant orientation (perpendicular or parallel to the row). In contrast to Girardin and Tollenaar (see e.g. figure 3 under field conditions, [14]), we did not, however, find an overall tendency for the upper leaves to become perpendicular to the row. Furthermore, algebraic means were not significantly different from zero: there was an equal probability for any leaf to display either on one side or the other of the zero mean orientation (see [8]).

\subsection{What should we do to assess the effect of leaf re-orientation on light absorption?}

Our study revealed noticeable azimuthal re-orientation in maize leaves until silking. Furthermore, we have previously shown [8] that the changes to the spatial position of maize leaves are mainly due to azimuthal movements: for a fully expanded leaf rank, lamina base inclination and lamina base height remain relatively constant between plants within a canopy. We therefore only tested the influence of leaf azimuthal re-orientation on light absorbed daily by the canopy. First, we modelled the time course of the canopy architecture using field measurements. We then designed hypothetical canopies that were characterized by various leaf azimuthal patterns. Light distribution was calculated within actual and hypothetical canopies. Finally, we compared the simulated daily light absorption efficiency of an actual canopy to the efficiency of the associated hypothetical canopies. 


\section{Modelling canopy architecture and light distribution}

\subsection{Experiment design}

A field experiment was carried out at Grignon (France, $48^{\circ}$ North) using the maize hybrid DEA. Maize was sown in the early summer of 1996 at two initial densities: 20 plants $\mathrm{m}^{-2}$ (D-density) and 10 plants $\mathrm{m}^{-2}$ (d-density). The rows ran northwest-south-east. Two plots at low density were obtained by removing plants during stem elongation (at 74 days after sowing (DAS)). In one plot of initial density 10 plants $\mathrm{m}^{-2}$ (d-density), three plants out of four within each row were removed to obtain a final density of 2.5 plants $\mathrm{m}^{-2}$ $\left(\mathrm{d}_{10 \rightarrow 2.5}\right.$-density). In another plot of initial density 10 plants $\mathrm{m}^{-2}$ (d-density), one row out of two were removed as well as nine plants out of ten within the remaining row, which resulted in a final density of 0.5 plants $\mathrm{m}^{-2}\left(\mathrm{~d}_{10 \rightarrow 0.5}\right.$-density). The plots were weeded, and plants were kept free of water stress by liberal drip irrigation.

\subsection{Description of plant architecture}

The 3D structure of the plants was measured with a magnetic digitizing device ([31], see e.g. [40] for more details). For each plant, the co-ordinates along the axis of the stem and the midrib of each leaf were recorded. The number of points per axis varied from 10 to 30 according to the length and the curvature of the organ. To examine densities of 10 and 20 plants $\mathrm{m}^{-2}$, data were obtained on 20 plants (four rows with five plants per row) at three stages of development: beginning of stem elongation (DAS $=60$, figure $4 a$ ), end of stem elongation (DAS $=74$, figure $4 b$ ) and post-silking

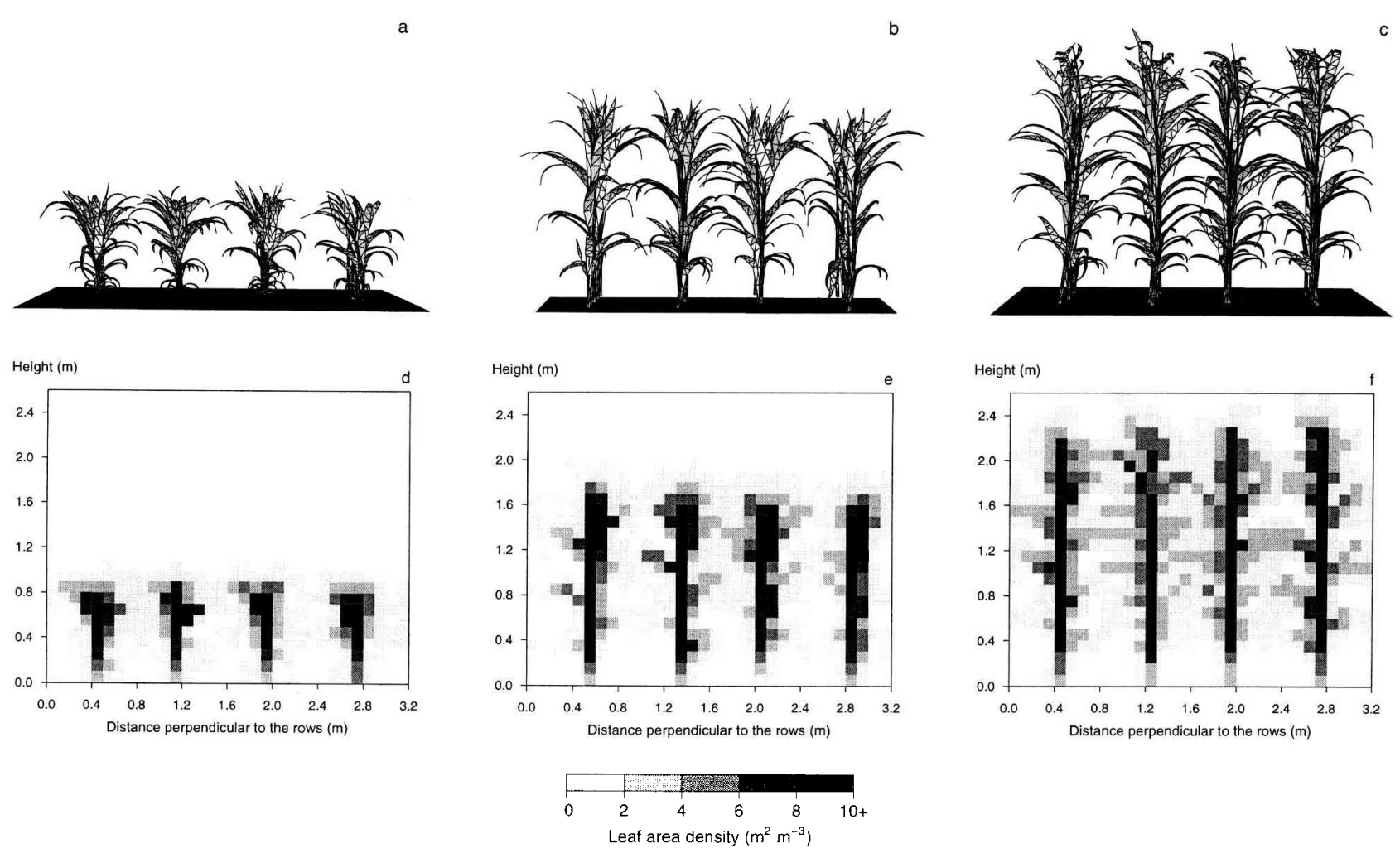

Figure 4. Three-dimensional (3D) description of the distribution of the aerial structure within a 10 plants $\mathrm{m}^{-2}$ canopy (d-density) at three stages of development: (a, d) DAS $=60$, (b, e) DAS $=74$ and (c, f) DAS $=90$. The 3D structure is represented (a-c) by a set of triangles and $(d-f)$ by an array of cells. 
Table I. Date of measurement and corresponding developmental stage, plant density and corresponding leaf area index (LAI) within the eight plots.

\begin{tabular}{llrc}
\hline $\begin{array}{l}\text { Date } \\
\text { (days after sowing) }\end{array}$ & \multicolumn{1}{c}{ Developmental stage } & $\begin{array}{c}\text { Density } \\
\left(\text { plants } \mathrm{m}^{-2}\right)\end{array}$ & LAI \\
\hline DAS $=60$ & $\begin{array}{l}\text { beginning of stem elongation } \\
\text { beginning of stem elongation } \\
\text { end of stem elongation }\end{array}$ & $\mathrm{D}(20)$ & 4.5 \\
DAS $=74$ & end of stem elongation & $\mathrm{d}(10)$ & 2.9 \\
DAS $=74$ & post-silking & $\mathrm{D}(20)$ & 6.4 \\
DAS $=90$ & post-silking & $\mathrm{d}(10)$ & 4.3 \\
DAS $=90$ & post-silking & $\mathrm{D}(20)$ & 6.7 \\
DAS $=90$ & (after removing plants at DAS $=74)$ & $\mathrm{d}(10)$ & 4.9 \\
DAS $=90$ & post-silking & $\mathrm{d}_{10 \rightarrow 2.5}(2.5)$ & 1.1 \\
& (after removing plants at DAS $=74)$ & $\mathrm{d}_{10 \rightarrow 0.5}(0.5)$ & 0.2 \\
\hline
\end{tabular}

(DAS $=90$, figure $4 c$ ). In the two plots at low density (2.5 and 0.5 plants $\mathrm{m}^{-2}$ ), data were recorded at DAS $=90$ on 12 plants (four rows with three plants per row). For each plot, the corresponding leaf area index (LAI) is shown in table I. Measurements were taken in the morning to minimize possible wind, water stress and heliotropism effects.

\subsection{Plant reconstruction}

The curvature of the axes of each plant (stem and leaf midribs) was obtained through digitizing. To reduce noise on the $3 \mathrm{D}$ structure, digitized coordinates were smoothed according to a cubic spline procedure (based on Lewis [23]). To describe the shape of the leaf blade, we established allometric relationships between lamina length and maximal width using a quadratic polynomial (based on Bonhomme and Varlet-Grancher [3]). The stem was reconstructed by measuring internode length and diameter. Each plant was geometrically represented by a set of about 1000 triangles and was visualized using the Freeware program Geomview (figure $4 a-c$ ). The reconstruction was indirectly validated by comparing the length of each measured lamina to the reconstructed one, and then the reconstructed plants to photographs (see [7] for more details).

\subsection{Modelling associated hypothetical canopies}

Since a major part of the variations in the aerial structure between neighbouring plants are due to azimuthal re-orientations, hypothetical canopies were simulated by simply rearranging the azimuthal positions of the leaves according to those observed in the actual canopy (see e.g. figure $5 a$ ). The actual orientation of the rows was maintained.

First, we generated two aerial structures commonly used in the literature for maize growth models. For one structure, azimuthal orientations of leaves were randomly rearranged (figure $5 b$ ). For the other structure, we generated opposite leaves in a vertical plane; the plane of each plant was determined by the azimuthal orientation of leaves 6 and 7 (figure $5 c$ ). Then, to estimate the range of variations of the daily light absorption efficiency (DLAE) following the azimuthal re-orientation of leaves, we generated two other associated hypothetical canopies, which represented extreme situations of competition. For one structure, leaves were rearranged opposite and perpendicular to the row (figure $5 d$ ) to reduce competition between leaves. For the other structure, leaves were rearranged opposite and parallel to the row (figure 5e) to increase competition between leaves. 


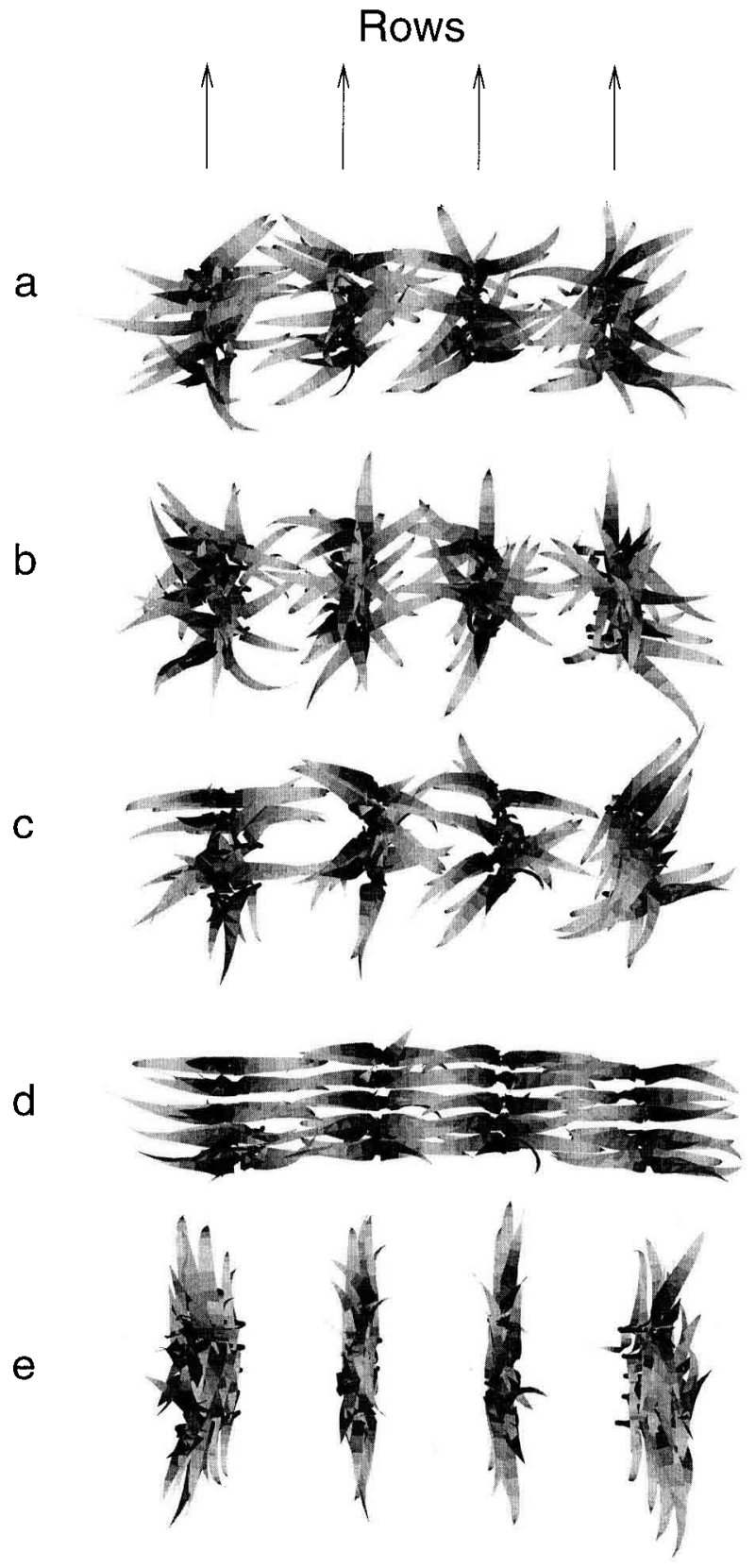

Figure 5. Vertical views of the actual and four simulated leaf azimuthal layouts within a 10 plants $\mathrm{m}^{-2}$ canopy (d-density) at $\mathrm{DAS}=74$ : (a) actual, (b) all the leaves randomly rearranged, (c) opposite leaves within a vertical plane, (d) all the leaves rearranged perpendicular to the row, (e) all the leaves rearranged parallel to the row.

\subsection{Simulation of light environment within the canopy}

A 3D volume-based version of the light transfer model RIRI (Radiation Interception in Row Intercropping [38]) was used to calculate irradiance distribution inside the canopies and the light absorption efficiency of the canopies. The model is based on the turbid-medium analogy. In this way, the canopy structure is abstracted by an array of $3 \mathrm{D}$ cells $(0.1 \mathrm{~m}$ wide) which may contain foliage or be empty (figure $4 d-f$ ). For each canopy cell, the leaf area density and the leaf angle distribution are calculated from the area and the orientation of the triangles (figure 4) (Andrieu, pers. comm.).

The model deals with direct and diffuse incident radiation and scattered radiation. Interception of direct incident radiation is calculated on the basis of simple geometrical considerations. A sample of directional beams enters the canopy from the top. The Beer-Lambert law is applied to calculate beam extinction within any visited cell and the probability of beam interception by the foliage elements. For each cell, beam interception depends on the direction of the beam, the leaf area density and the leaf distribution angle within the cell, and the size of the cell. Diffuse incident radiation is treated as direct incident radiation, by integrating directional interception contributions over the whole sky. The sky is divided into solid angle sectors: nine classes of height angles (intervals of $10^{\circ}$ ) and 12 classes of azimuth angles (intervals of $30^{\circ}$ ). The amount of incident diffuse radiation coming from each angle sector is computed from the standard OverCast sky distribution [26]. For scattering radiation, the directional distribution of the radiation scattered by the soil surface and the foliage elements is first assessed using a phase function, and the interception of the scattered radiation is then calculated. The radiative balance of the canopy is solved by using an adaptation of the radiosity method [30] which makes it possible to obtain the radiation absorbed by each cell of the canopy (see [38] for more details).

For each plot, simulations of light absorption were performed in the photosynthetic active radiation waveband (PAR, 400-700 nm) from six values 
of daily global radiation (table $I I$ ). Instantaneous values of direct radiation and diffuse radiation were simulated for each time step $(0.1 \mathrm{~h})$, as described in Spitters et al. [42] and Allirand (pers. comm.). The latter assumes a seesawing at the instantaneous scale between a completely clear sky and an entirely overcast sky (see [7] for details). For each cell of the canopy, the daily average foliage irradiance was calculated from the instantaneous values. The daily light absorption efficiency (DLAE) of the canopy was evaluated by integrating instantaneous and local (i.e. each cell) values.

The model requires the optical properties of the foliage and uses the classical assumption of equality between leaf reflectance and leaf transmittance. Since we found that leaf reflectance and transmittance were relatively constant within the canopies, at least during the studied period, we used only one average value of reflectance-transmittance (0.07). Land soil reflectance was set equal to 0.10 (see [7] for more details).

The light model had previously been validated using radiation measurements for several crops, especially maize canopies (see $[37,38]$ ).

\section{Influence of leaf azimuthal re-orientations on light absorbed by the canopy}

\subsection{Daily light absorption efficiency in associated actual and hypothetical canopies}

Because leaves explore a large range of azimuths during their growth, we studied the effect of azimuthal re-orientations on light absorbed daily by canopies of various leaf area indexes (LAI). For each plot (table I), all the values of DLAE simulated within the hypothetical canopies were normalized by the value of DLAE simulated within the associated actual canopy (figure 6).

Regardless of canopy LAI, the three aerial structures (actual (figure 5a), random (figure 5b) and opposite (figure $5 c$ )) had similar values of normalized daily light absorption efficiency (NDLAE). As
Table II. Characteristics of the daily incident radiation simulated for the six values of daily global radiation used in computations of light absorption.

\begin{tabular}{cc}
\hline $\begin{array}{c}\text { Daily global radiation } \\
\left(\mathrm{MJ} \mathrm{m}^{-2}\right)\end{array}$ & $\begin{array}{c}\text { Daily ratio } \\
\text { diffuse radiation/global radiation }\end{array}$ \\
\hline 5 & 1.00 \\
10 & 0.89 \\
15 & 0.79 \\
20 & 0.61 \\
25 & 0.43 \\
30 & 0.25 \\
\hline
\end{tabular}

the LAI of the canopy varied from $1.1\left(\mathrm{~d}_{10 \rightarrow 2.5}\right.$-density at DAS $=90$ ) to 6.7 (D-density at DAS $=90$ ), the differences in NDLAE between these three kinds of aerial structure were insignificant (less than $3 \%$ (figure 6 )). However, in a canopy of LAI 2.9 (d-density at DAS $=60$ ), the random azimuthal distribution of leaves could have caused a $3 \%$ decrease in NDLAE compared to the associated actual layout. Since leaves tended to display their surface in the space between rows [37], a random azimuthal distribution of leaves would mean stronger clumping within the rows. This might lead to a decrease in the light absorbed by leaves.

Considering hypothetical unrealistic canopy structures (all the leaves perpendicular to the row (figure $5 d$ ) or all the leaves parallel to the row (figure 5e)) made it possible to observe significant differences in NDLAE between these hypothetical canopy structures and the associated actual canopy structure (figure 6). In the perpendicular configuration, repartition of the foliage within the canopy is regular (figure $5 d$ ), and NDLAE is significantly higher within the perpendicular layout than in the actual one for canopies of LAI 2.9 and 4.5, 6 and $3 \%$, respectively (figure 6 ). For open canopies $(\mathrm{LAI}=1.1)$ or dense canopies $(\mathrm{LAI}=6.7)$, the differences between actual and perpendicular structures were insignificant in terms of daily light absorption (less than $3 \%$ (figure 6)). If all the leaves were parallel to the rows, foliage clumping within the rows would be extremely dense (fig ure $5 e$ ). This structure could lead to a large decrease 


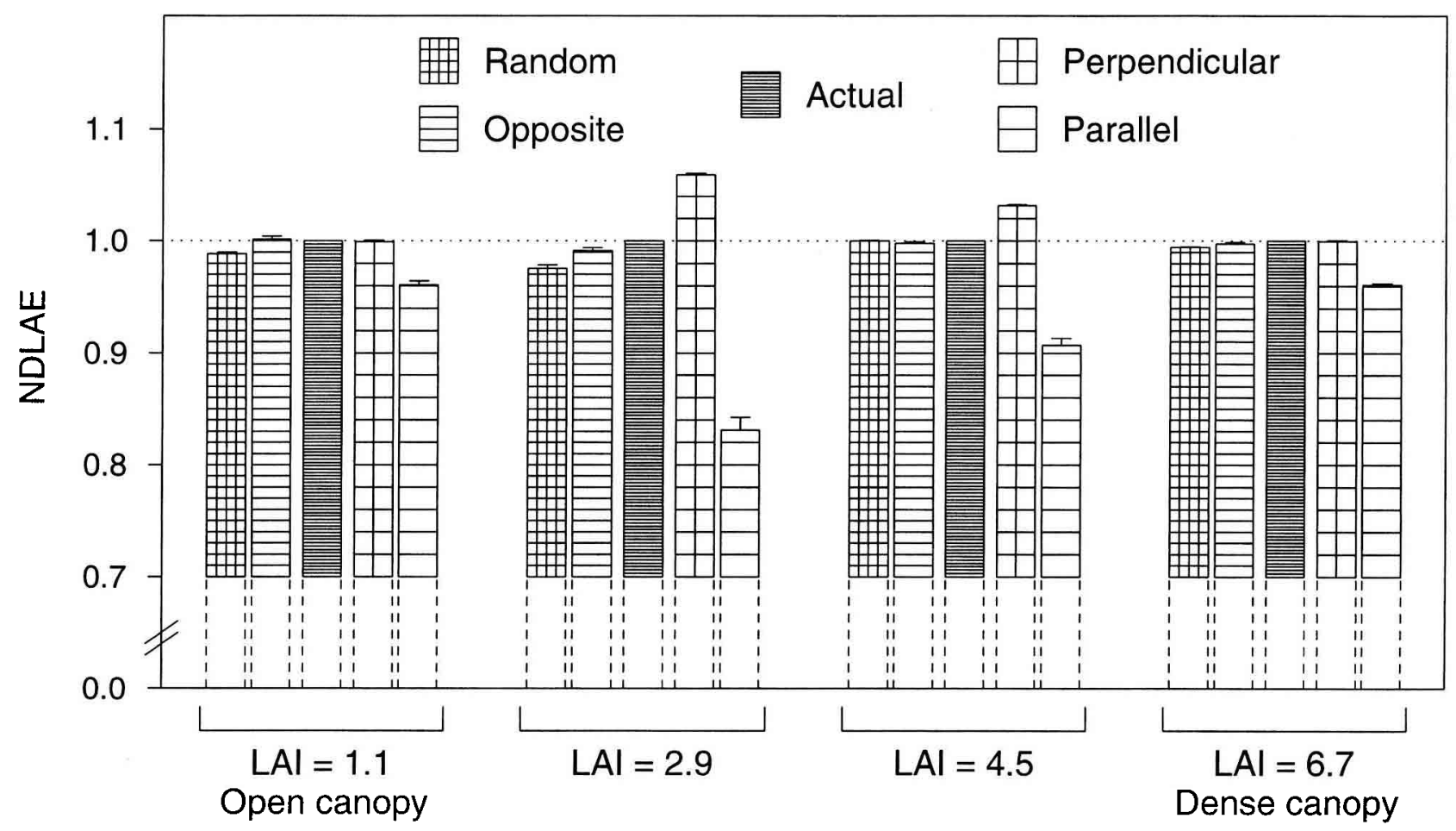

Figure 6. Mean and standard deviation of the normalized daily light absorption efficiency (NDLAE) of actual and associated hypothetical canopies for which the azimuthal positions of leaves were rearranged to obtain configurations described in figure 2. For each plot, the values of DLAE simulated within the hypothetical canopies are normalized by the value of DLAE simulated within the associated actual canopy. Mean and standard deviation are calculated with the six daily incident radiation characteristics shown in table II.

in NDLAE compared to the actual structure. As previously stated, the greater differences in NDLAE between parallel and actual layouts were observed for canopies of LAI 2.9 and 4.5, 17 and $10 \%$, respectively (figure 6). For open or dense canopies $(\mathrm{LAI}=1.1$ and $\mathrm{LAI}=6.7$ ), these differences were insignificant (less than $3 \%$ (figure 6)).

The range of NDLAE variations, resulting from variations in azimuthal positions of leaves, was determined for each canopy (table $I$ ) from the highest NDLAE (generally obtained with the perpendicular layouts) and the lowest NDLAE (generally obtained with the parallel layouts). Three LAI domains were identified (figure 7). For the open canopies (LAI less than 2 or 3), even a strong variation in the azimuthal position of leaves would lead to a low range of NDLAE variations (less than $5 \%$ ). A similar behaviour was observed for the dense canopies (LAI above 5 or 6 , range less than
$10 \%)$. Conversely, for the canopies characterized by a LAI of between 2.5 and 5.5, changes to the azimuthal orientation of leaves could cause larger changes in NDLAE: changes in the aerial structure from a perpendicular leaf azimuthal layout to a parallel one could lead to a range of NDLAE variations of $25 \%$ (figure 7 ).

\subsection{Distribution of daily leaf irradiance within the canopy}

Figure 8 shows the partitioning of daily leaf irradiance by horizontal parallelepiped of section $0.1 \times 0.1 \mathrm{~m}^{2}$ within the actual canopy as well as the two associated extreme configurations. The similarity between the leaf irradiance profiles within the actual leaf azimuthal layout and the perpendicular one (figure $8 a, b$, and figure $8 d, e$ ) was expected (see figure 5). Conversely, the leaf irradiance 
Figure 7. Range of normalized daily light absorption efficiency (NDLAE) calculated with the hypothetical structure generating the highest NDLAE (NDLAE ${ }_{M}$ ) while generating the lowest NDLAE (NDLAE $)_{m}$ ). The eight points correspond to the eight canopies described in table $I$. For each plot, mean and standard deviation are calculated with the six daily incident radiation characteristics shown in table $I I$.
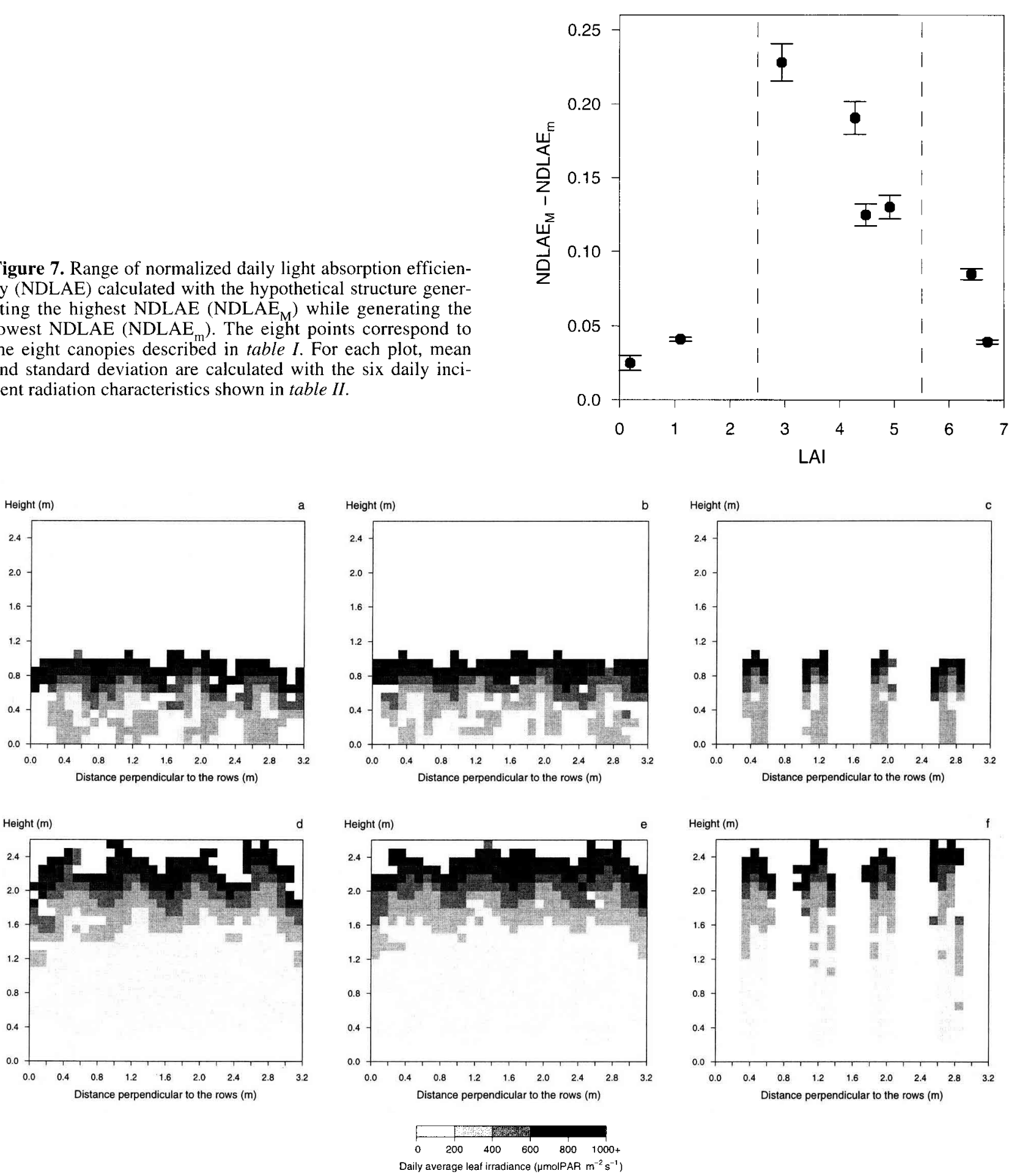

Figure 8. Vertical profiles, by horizontal parallelepiped $\left(0.1 \times 0.1 \mathrm{~m}^{2}\right.$ section $)$, of daily average leaf irradiance calculated for a sunny day $\left(25 \mathrm{MJ} \mathrm{m}^{-2}\right)$ within a 10 plants $\mathrm{m}^{-2}$ canopy (d-density) for three associated leaf azimuthal layouts at two stages of development: (a) actual layout at DAS $=60$, (b) perpendicular layout at DAS $=60$, (c) parallel layout at DAS $=60$, (d) actual layout at DAS $=90$, (e) perpendicular layout at DAS $=90$, (f) parallel layout at $\mathrm{DAS}=90$. 
profiles varied greatly between the actual leaf azimuthal layout and the parallel one figure $8 a, c$, and figure $8 d, f$ ). However, this large difference led to relatively low differences in NDLAE values between these two leaf configurations: only $17 \%$ within a canopy of LAI 2.9 (see figure 6). Since sunbeam inclination is always less than $65^{\circ}$ at the latitude of Grignon ( $48^{\circ}$ North), strong leaf clumping within the row would increase the daily light absorbed by the lower layers of the canopy in the parallel layout (figure $8 c, e$ ). This configuration would partially compensate for the low light absorption efficiency within the row due to leaf clumping, which might explain the relatively low differences in NDLAE between these extreme leaf configurations.

\section{Discussion}

\subsection{Leaf position as a reaction to local environment}

To explain leaf azimuthal re-orientation, we suggested that leaf positioning might be a reaction to changes in the local environment rather than an optimal strategy of leaf positioning developed by the plant. Each individual leaf could detect and avoid leaf clumping in reaction to either contacts or changes in local light microclimate. This assumption was supported by previous work [8], which reported no clear relationship between internode rotation and leaf azimuthal rotation.

The first hypothesis, reaction to foliage accumulation, might be considered: leaf azimuthal dispersion was more important for initial plant orientation within the row than perpendicular to the row. Investigating light profiles (figure 8) enables us to discuss the second hypothesis of local leaf acclimation to light microclimate. Since leaf azimuthal re-orientation mainly occurred during the leaf growing period, light could only affect leaf positioning during this short period of about 10 days. We could first imagine that leaf re-orientation is due to local variations in the quantity of absorbed energy (PAR radiation). Each individual leaf could develop a strategy to maximize light capture. This optimization process occurs for a short period (only 10 days). Since it affects a reduced number of leaves (only developing leaves partially shaded by upper ones), its results on light absorption by the whole canopy could be lower than expected. The upper growing leaves received about the same quantity of daily radiation whatever their orientation. Consequently, the changes in the azimuthal positioning of leaves would be a reaction to some other factor than quantity of radiation intercepted; the quality of scattered radiation (blue, red/far-red ratio) received from the lower mature leaves could play a role. These changes to light quality caused by neighbouring leaves could influence the phototropism of growing leaves $[2,43]$. Such a reaction might allow the leaves to avoid indirectly selfshading in the middle layers of the canopy, but this would only be partial because of the low mobility of mature leaves and the short duration of the leaf growing period. Whatever the variable, light quantity or light quality, its daily changes are likely to have little effect on the light absorbed daily by the canopy.

However, generating realistic situations of leaf re-orientation (opposite (figure $5 c$ ) or random (figure $5 b$ )) enables us to investigate both the dependence and the independence of the azimuthal orientation of successive leaf ranks within any plant with respect to daily light absorption.

The comparison between actual (figure 5a) and opposite (figure $5 \mathrm{c}$ ) patterns indicates that plants should not benefit from re-orientating leaves with respect to their distichous plane (figure 6), at least in temperate regions. At the latitude of Grignon ( $48^{\circ}$ North), sun angles are always less than $65^{\circ}$ and they allow a good penetration of incoming radiation within the canopy when leaves are superimposed (figure $8 c, f$ ). That is in contrast with Girardin and Tollenaar [15], who reported that the azimuthal shift of successive leaves tended to reduce interplant competition for incident radiation. It would be worthwhile to carry out our study in the light conditions of subtropical latitudes, which correspond to the conditions encountered by the primitive maize plants. Superimposition of leaves associated with vertical sunbeams around 
midday might be disadvantageous for light absorption. Maize plants in subtropical regions may have developed strategies to avoid unfavourable opposite leaf layouts.

The comparison between actual (figure $5 a$ ) and random (figure $5 b$ ) patterns enables us to test the effect of independence in the leaf azimuthal orientation of successive leaf ranks on daily light absorption. We showed that the actual layout is similar to the random one for light absorption. That is connected with the observed tendency for successive leaves to display randomly distributed azimuths, especially the upper ones (figure $2 c, f$ ). This random leaf positioning could be altered by a row effect, as reported by Sinoquet and Bonhomme [37], among others.

\subsection{Light absorption efficiency in heterogeneous maize canopies}

We showed through simulation of light absorption that leaf azimuthal orientations were likely to have no significant effect on the light absorbed daily by the canopy (figure 6). We had to consider extreme and unrealistic leaf azimuthal layouts (all the leaves initially perpendicular to the row or within the row) in order to simulate significant variations in daily light absorption efficiency. An explanation of the slight discrepancies in NDLAE between associated actual and hypothetical canopies was provided by the similarity of daily leaf irradiance profiles (see figure $8 a, b$ and figure $8 d, e)$. Therefore, the hypothesis of leaf azimuthal layouts classically used for a maize canopy (random or opposite layout) is suitable for crop-functioning models.

Investigating the range of NDLAE variations helped us to distinguish three LAI domains that corresponded to three domains of crop heterogeneity, according to competition between leaves of neighbouring plants for space occupation and light interception (figure 7). First, our canopies with LAI less than 2.5 corresponded to low plant densi-

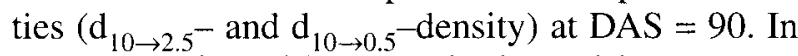
these canopies with strong horizontal heterogeneity, competition was poor between neighbouring plants within and between rows. Azimuthal variation in leaf position led to slight changes in local light microclimate. Our canopies of LAI greater than 5.5 corresponded to a 20 plants $\mathrm{m}^{-2}$ density on and after DAS $=74$. In these canopies with relatively low horizontal heterogeneity, competition between neighbouring plants within and between rows was likely to be strong. As in the preceding case, azimuthal variation in leaf positions led to mild changes in local light microclimate. Our canopies with LAI between 2.5 and 5.5 corresponded to a 10 plants $\mathrm{m}^{-2}$ density between $\mathrm{DAS}=60$ and DAS $=90$. In these fairly heterogeneous canopies, competition was expected to be high between neighbouring plants within the rows, even though competition between rows was likely to be low. Azimuthal variation in leaf position caused greater variation in local light microclimate than in the two canopies of the first type.

Our study may have implications for agronomic modelling. Light absorption caused by leaf azimuthal re-orientation differed most in canopies with normal agronomic density (10 plants $\mathrm{m}^{-2}$ ) between the onset of stem elongation and silking. This developmental period corresponds to a major phase of leaf biomass accumulation, and the produced leaf surface will later on be responsible for the current photosynthesis filling the grain [13]. Therefore, azimuthal positioning of leaves towards the end of the vegetative period might influence the final grain yield of the canopy. A more regular distribution of foliage within fairly heterogeneous canopies would increase light absorption, then crop yield. This was partially observed in natural conditions, where leaves showed a tendency to display between rows, especially after stand closure. This study emphasized the need to take into account the horizontal distribution of foliage in the case of fairly heterogeneous canopies such as row crops.

\section{Conclusion}

We previously demonstrated large azimuthal reorientation in maize leaves, mainly during the leaf growing period [8]. To explain leaf movement, we hypothesized that leaves react to their local envi- 
ronment, especially a light microclimate. However, simulations using a 3D volume-based model of radiative exchange [38] showed that leaf re-orientation had no significant effect on light absorbed daily by the canopy, at least in the light conditions of temperate regions. No previous studies contradict this, but further investigations are required to validate this result on other crops. It would also be interesting to consider subtropical light conditions and to re-examine the effect of superimposed leaves under these conditions. Thus, for heterogeneous maize canopies, the classical assumptions on leaf azimuthal layouts are suitable for assessing aspects of crop functioning, such as crop biomass production, that require a period of integration of at least 1 day. This result is not confirmed by similar studies involving a smaller period of integration [7] and it may be not applied at the organ (i.e. leaf) level. Thus, in the case of period of integration smaller than 1 day, architectural plant models [12] should be coupled with surface-based models of radiative transfer [5] and not to volume-based models to investigate the hypothesis of leaf optimal positioning in order to maximize light capture.

Acknowledgements: We thank Dr B. Andrieu for helpful discussions and comments and providing us with his 'surface-to-volume' procedure. We gratefully acknowledge Dr H. Sinoquet for valuable consultation about the used light transfer model RIRI that he developed and, with P. Rivet, on the digitizing system, Polhemus. We are grateful to Dr P. Lewis for providing us with the spline procedure that he implemented. We also thank P. Bonchrétien, M. Lauransot, C. Civet and $\mathrm{M}$. and J. Chartier for their technical contribution.

\section{References}

[1] Assémat L., Champroux G., Ney B., Measuring light interception by weeds in maize crops, in: Sinoquet H., Cruz P. (Eds.), Ecophysiology of Tropical Intercropping, Inra Editions, Paris, 1995, pp. 109-114.

[2] Ballaré C.L., Scopel A.L., Sanchez R.A., Far-red radiation reflected from adjacent leaves: an early signal of competition in plant canopies, Science 247 (1990) 329-331.

[3] Bonhomme R., Varlet-Grancher C., Estimation of the gramineous crop geometry by plant profiles includ- ing leaf width variations, Photosynthetica 12 (1978) 193-196.

[4] Chartier P., Étude du microclimat lumineux dans la végétation, Ann. Agron. 17 (1966) 571-602.

[5] Chelle M., Andrieu B., Radiative models for architectural modelling, Agronomie 19 (1999) 225-240.

[6] Dauzat J., Hautecœur O., Simulation des transferts radiatifs sur maquettes informatiques de couverts végétaux, in: Actes du colloque, Mesures physiques et signatures en télédétection, European Space Agency, Paris, 1991, vol. 1, pp. 415-418.

[7] Drouet J.L., Variations de la disposition spatiale et de la teneur en azote des feuilles d'un peuplement de maïs en phase végétative. Étude par simulation de l'influence de ces variations sur la photosynthèse potentielle du couvert, Ph.D. thesis, Institut national agronomique, Paris-Grignon, 1998.

[8] Drouet J.L., Moulia B., Spatial re-orientation of maize leaves affected by initial plant orientation and density, Agric. For. Meteorol. 88 (1997) 85-100.

[9] Duncan W.G., Leaf angles, leaf area, and canopy photosynthesis, Crop Sci. 11 (1971) 482-485.

[10] Fisher N.I., Statistical Analysis of Circular Data, University Press, Cambridge, 1993.

[11] Fortin M.C., Pierce F.J., Leaf azimuth in stripintercropped corn, Agron. J. 88 (1996) 6-9.

[12] Fournier C., Andrieu B., ADEL-maize: an Lsystem based model for the integration of growth processes from the organ to the canopy. Application to regulation of morphogenesis by light availability, Agronomie 19 (1999) 313-327.

[13] Gay J.P., Le cycle du maïs, in: Gallais A. (Ed.), Physiologie du maïs, Inra Editions, Paris, 1984, pp. $1-11$.

[14] Girardin P., Leaf azimuth in maize canopies, Eur. J. Agron. 1 (1992) 91-97.

[15] Girardin P., Tollenaar M., Leaf azimuth in maize: origin and effects on canopy patterns, Eur. J. Agron. 1 (1992) 227-233.

[16] Girardin P., Tollenaar M., Effects of intraspecific interference on maize leaf azimuth, Crop Sci. 34 (1994) 15l-155.

[17] Givnish T.J., Adaptation to sun and shade: a whole plant perpective, Aust. J. Plant Physiol. 15 (1988) 63-92.

[18] Goel N.S., Models of vegetation canopy reflectance and their use in estimation of biophysical parameters from reflectance data, Remote Sens. Rev. 4 (1988) $1-212$. 
[19] Goel N.S., Rozehnal I., Thompson R.L., A computer graphics based model for scattering from objects of arbitrary shapes in the optical region, Remote Sens. Environ. 36 (1991) 73-104.

[20] Hikosaka K., Hirose T., Leaf angle as a strategy for light competition: optimal and evolutionary stable light-extinction coefficient within a canopy, Ecoscience 4 (1997) 501-507.

[21] Ledent J.F., Henkart T., Jacobs B., Phénologie du maïs, visualisation de la croissance et du développement, Rev. Agric. 43 (1990) 391-408.

[22] Lemeur R., A method for simulating the direct solar radiation regime in sunflower, Jerusalem artichoke, corn and soybean canopies using actual stand structure data, Agric. Meteorol. 12 (1973) 399-410.

[23] Lewis P., A Botanical Plant Modelling System for Remote Sensing Simulation Studies, Ph.D. thesis, University of London, UK, 1996.

[24] Loomis R.S., Williams W.A., Productivity and morphology of crop plants: pattern with leaves, in: Austin J.D., Haskins F.A., Sullivan C.Y., Van Bavel C.H.M. (Eds.), Physiological Aspects of Crop Yields, Am. Soc. Agron., Madison, Wisconsin, 1969, pp. $27-41$.

[25] Monsi M., Saeki T., Über Lichtfaktor in den Pflanzengesellschaften und seine Bedeutung für die Stoffproduktion, Jpn. J. Bot. 14 (1953) 22-52.

[26] Moon P., Spencer D.E., Illumination from a non-uniform sky, Trans. Illum. Eng. Soc. 37 (1942) 707-712.

[27] Myneni R.B., Asrar G., Kanemasu E.T., Lawlor D.J., Impens, I., Canopy architecture irradiance distribution on leaf surfaces and consequent photosynthetic efficiencies in heterogeneous plant canopies. I. Theoretical considerations, Agric. For. Meteorol. 37 (1986) 189-204.

[28] Myneni R.B., Ross J., Asrar G., A review on the theory of photon transport in leaf canopies, Agric. For. Meteorol. 45 (1989) 1-153.

[29] Nichiporovich A.A., Properties of plant crops as an optical system, Soviet Plant Physiol. 8 (1961) $428-435$.

[30] Ozisik N.M., Radiative Transfer, Wiley InterScience, New York, 1981.

[31] Polhemus, 3SPACE Fastrak User's Manual, Revision F, Polhemus, Colchester, VT, USA, 1993.

[32] Prévot L., Aries F., Monestiez P., Modélisation de la structure géométrique du maïs, Agronomie 11 (1991) 491-503.
[33] Prusinkiewicz P., A look at the visual modeling of plants using L-systems, Agronomie 19 (1999) 211-224.

[34] Ross J., The Radiation Regime and Architecture of Plant Stands, Dr W. Junk Publishers, The Hague, 1981, pp. 90-121.

[35] Ross J., Nilson T., The spatial orientation of leaves in crop stands and its determination, in: Nichiporovitch A.A. (Ed.), Photosynthesis of Productive Systems. Acad. Sci. USSR, Israel Progr. for Sci. Trans., Jerusalem, 1967, pp. 86-99.

[36] Sinoquet H., Andrieu B., The geometrical structure of plant canopies: characterization and direct measurement methods, in: Varlet-Grancher C., Bonhomme R., Sinoquet H. (Eds.), Crop Structure and Light Microclimate, Inra Editions, Paris, 1993, pp. 131-158.

[37] Sinoquet H., Bonhomme R., Modelling of solar radiation interception in row crops. II. Crop geometry and validation of the model, Agronomie 9 (1989) 619-628.

[38] Sinoquet H., Bonhomme R., Modeling radiative transfer in mixed and row intercropping systems, Agric. For. Meteorol. 62 (1992) 219-240.

[39] Sinoquet H., Moulia B., Bonhomme R., Estimating the three-dimensional geometry of a maize crop as an input of radiation models: comparison between three-dimensional digitizing and plant profiles, Agric. For. Meteorol. 55 (1991) 233-249.

[40] Sinoquet H., Rivet P., Drouet J.L., Méthodes de digitalisation et de visualisation 3D de l'architecture des plantes, in: Actes du séminaire Modélisation architecturale, 10-12 March 1997, Département de Bioclimatologie Inra, Paris, 1997, pp. 31-37.

[41] Sinoquet H., Varlet-Grancher C., Bonhomme R., Modelling radiative transfer within homogeneous canopies: basic concepts, in: Varlet-Grancher C., Bonhomme R., Sinoquet H. (Eds.), Crop Structrure and Light Microclimate, Inra Editions, Paris, 1993, pp. 207-228.

[42] Spitters C.J.T., Toussaint H.A.J.M., Goudriaan J., Separating the diffuse and direct component of global radiation and its implication for modeling canopy photosynthesis. I. Components of incoming radiation, Agric. For. Meteorol. 38 (1986) 217-229.

[43] Varlet-Grancher C., Gautier H., Plant morphogenetic responses to light quality and consequences for intercropping, in: Sinoquet H., Cruz P. (Eds.), Ecophysiology of Tropical Intercropping, Inra Editions, Paris, 1995, pp. 231-256.

[44] Whigham D.K., Woolley D.G., Effect of leaf orientation, leaf area, and plant densities on corn production, Agron. J. 66 (1974) 482-484. 